\title{
Cristalização: Síntese de Sais Duplos
}

\author{
CLEMENTINA TEIXEIRA*, ANA TAVARES SOUSA**, ISABEL TRIGUEIROS**
}

\subsection{INTRODUÇÃO}

As técnicas de cristalização encontram-se fortemente implementadas em muitos domínios da Química: mantêm a sua importância como técnicas clássicas separativas ou de purificação à escala laboratorial e, industrialmente, estão ligadas à produção de produtos químicos de grande tonelagem, tais como o açúcar, a ureia, os zeólitos, os fármacos, etc. Por outro lado, os processos de crescimento de cristais tiveram recentemente uma grande evolução: aparecem sistematicamente associados à síntese química, na obtenção de monocristais de pequenas dimensões para determinações de estruturas e no fabrico de uma vasta gama de novos materiais de interesse tecnológico (proteínas, polímeros, monocristais de morfologia ou hábito modificado para aplicações específicas em óptica e electrónica, etc.).

Apesar do avanço tecnológico e da existência de aparelhagem muito sofisticada em todas estas áreas, a cristalização pode ser introduzida, com grande simplicidade e de forma muito atractiva, utilizando apenas substâncias que formem monocristais com relativa facilidade. É neste âmbito que se tem vindo a desenvolver, desde 1994 e com bastante sucesso ao nível do ensino da Química [1-3], a cristalização de sais iónicos e de outras substâncias sobre suportes rugosos (rochas, conchas, arame e vidro), os quais estimulam fortemente o crescimento dos cristais, devido ao facto de proporcionarem um elevado número de núcleos de cristalização à sua superfície e de estabelecerem interacções muito fortes com os substratos em solução. O método geral consiste em preparar, por aquecimento, soluções aquosas saturadas de diversos sais iónicos, escolhidos entre aqueles cuja solubilidade aumenta com a temperatura. Estas soluções tornam-se sobressaturadas por arrefecimento controlado à temperatura ambiente, depositando o excesso de material dissolvido sobre os suportes, na forma de cristais bem desenvolvidos e atractivos, podendo atingir dimensões razoáveis (vários centímetros).

Ao introduzir uma forte componente lúdica nas preparações e explorando a beleza magnífica dos cristais, aumenta-se a receptividade dos alunos em relação a um grande número de conceitos básicos, tais como: reacções em solução, variação da so-

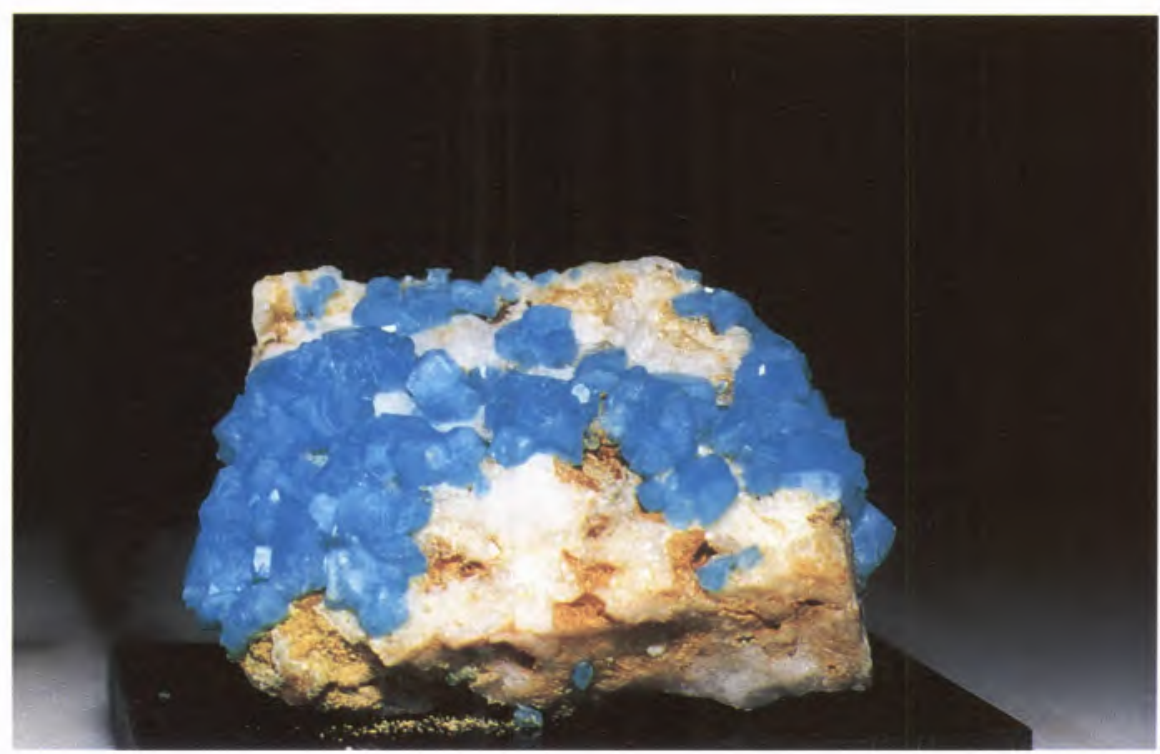

Fig. 1 - Schönite de amónio e cobre (II) [2]

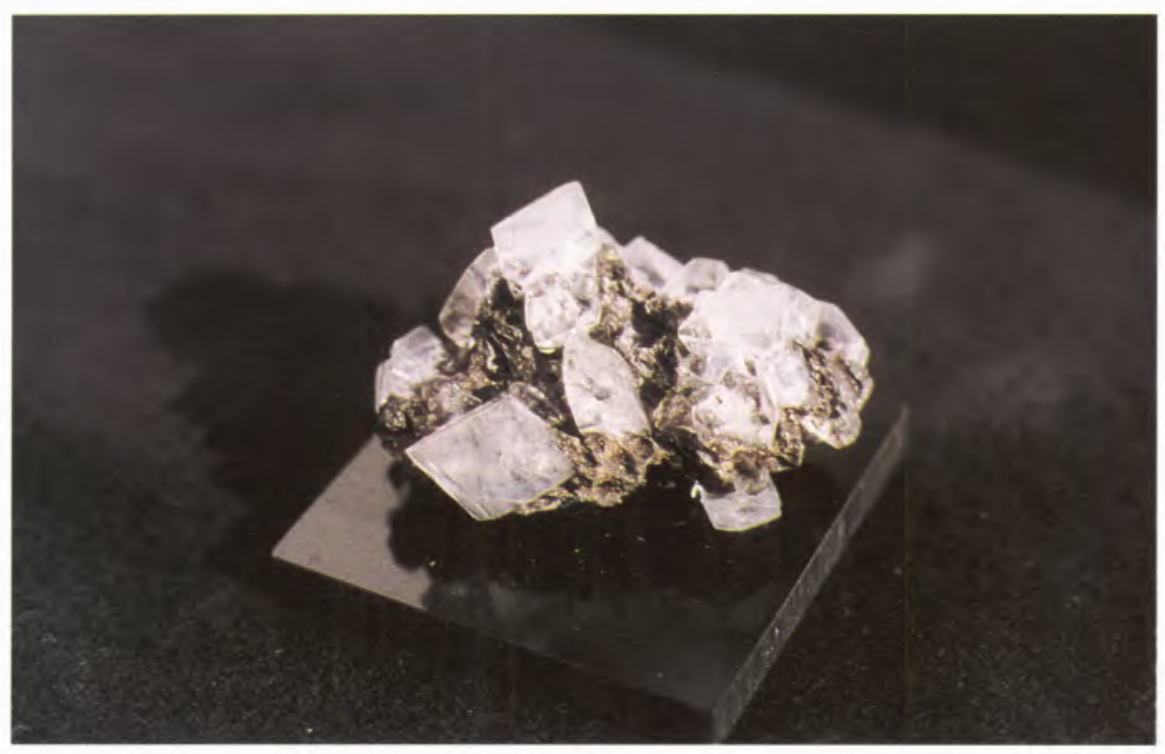

Fig. 2 - Schönite de amónio e magnésio [2] lubilidade com a temperatura, soluções saturadas e sobressaturadas, equilíbrio de precipitação, modos para exprimir concentrações de soluções, sistemas de cristalização, estado sólido e classificação de cristais, etc.

Nos parágrafos que se seguem descreve-se a aplicação deste método à síntese e caracterização de sais du- 
plos, ao nível do ensino secundário. O trabalho prático que a seguir se propõe foi executado por 40 alunos do $11^{\circ}$ ano ( 2 turmas), na disciplina de Técnicas Laboratoriais de Química, bloco II (TLQ II).

\subsection{Síntese de sais duplos}

A síntese de sais duplos é introduzida no programa de TLQ II. Estes sais podem ser sintetizados a partir da reacção entre os sais simples, nas respectivas proporções estequiométricas, sendo a combinação de diferentes catiões e aniões praticamente ilimitada. Porém, algumas das sínteses não são aconselháveis ao nível do ensino secundário, por serem demasiado complexas, originarem produtos instáveis (sais eflorescentes, deliquescentes ou apresentando outro tipo de decomposição ${ }^{1}$ ) ou ainda por envolverem espécies de toxicidade reconhecida. No entanto, é possível fazer uma listagem suficientemente vasta para que numa turma cada grupo possa sintetizar um sal diferente, diversificando, assim, o número de exemplos a apresentar aos alunos e permitindo um confronto de resultados com os colegas. Pode-se ainda fazer a cristalização sobre um suporte rugoso (rocha ou concha) e estudar a sua influência no processo.

Os sulfatos são sais de grande uso nas escolas devido ao seu baixo custo e à multiplicidade das suas utilizações. Assim, propomos fazer a síntese de sais duplos a partir de sulfatos simples, considerando duas famílias: as schönites e os alúmenes [4].

As schönites são sais com um catião monovalente e um catião bivalente, de fórmula geral $\mathrm{M}_{2}{ }^{\mathrm{I}} \mathrm{M}^{\mathrm{II}}\left(\mathrm{SO}_{4}\right)_{2} \cdot 6 \mathrm{H}_{2} \mathrm{O}$ (figuras 1 e 2 ). São todas isoestruturais, cristalizando no sistema monoclínico. Os sais duplos desta família são, na sua maioria, bastante estáveis e menos solúveis em água do que os sais simples que os compõem. Os cristais que se obtêm são, em geral, euédricos, mostrando claramente o sistema de cristalização. Podem-se ainda obter misturas homogéneas de várias schöni- tes, o que permite introduzir o conceito de solução sólida que, normalmente, não é de apreensão fácil para os alunos.

Os alúmenes são sais com um catião monovalente e um catião tri- valente, de fórmula geral $\mathrm{M}^{\mathrm{I}} \mathrm{M}^{\mathrm{III}}\left(\mathrm{SO}_{4}\right)_{2} \cdot 12 \mathrm{H}_{2} \mathrm{O}$ (figura 3). Alguns fundem a temperaturas inferiores a $100{ }^{\circ} \mathrm{C}$, tornando acessível a determinação do ponto de fusão. Ao contrário das schönites, alguns destes sais são eflorescentes ou apresen-



Fig. 3 - Alúmen de potássio [2]

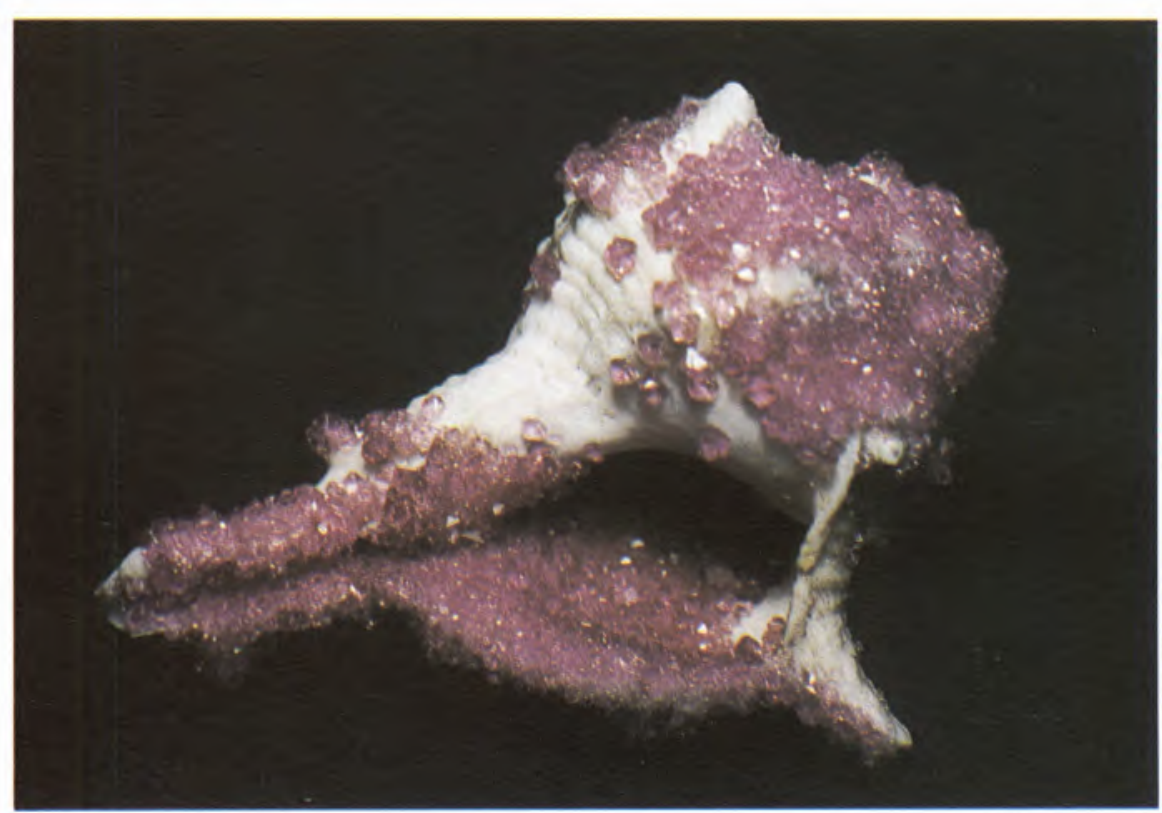

Fig. 4 - Solução sólida de alúmen de potássio e alúmen de crómio "ametistas" [2] 
Tabela 1 - Condições de preparação de sais duplos

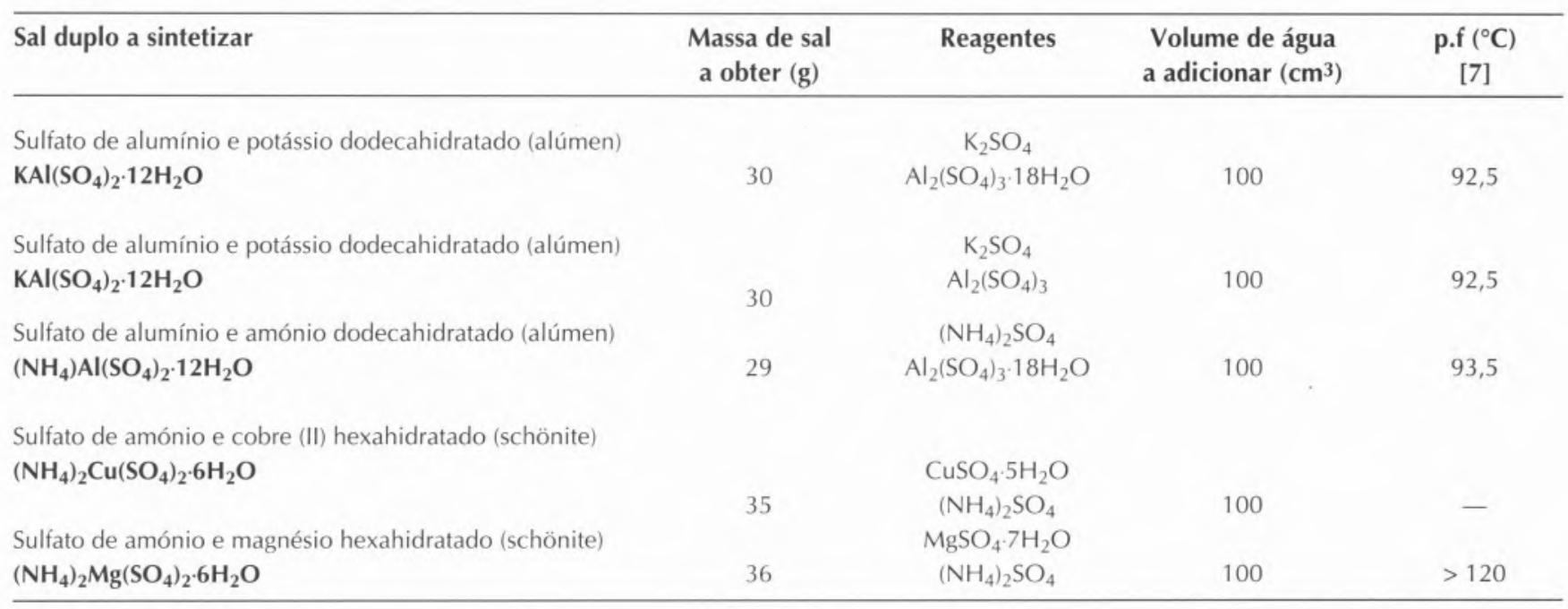

tam outro tipo de decomposição. Cristalizam no sistema cúbico, formando monocristais de razoável dimensão (vários centímetros), sendo possível obter soluções sólidas por cocristalização de sais isoestruturais (figura 4).

A síntese de sais duplos pode ser aproveitada para aprofundar ou aplicar conhecimentos anteriormente abordados nas disciplinas de Ciências Físico-Químicas (escrita e acerto de equações químicas, cálculos estequiométricos, rendimento de um processo, noção de $\mathrm{pH}$ ) e de TLQ I (cristalização, determinação experimental do ponto de fusão e sua utilização como critério de pureza). Permite ainda abordar alguns conceitos que os alunos têm normalmente dificuldade em apreender, como por exemplo, o conceito de solução sólida, a diferença entre precipitação e cristalização [5] e o facto de as soluções salinas não serem necessariamente neutras. A utilização de um suporte rugoso para induzir a cristalização permite também evidenciar a possibilidade de ocorrência de reacções paralelas num sistema químico: a escolha de conchas ou rochas carbonatadas provoca reacção moderada ou intensa com as soluções ácidas dos sais (soluções contendo $\mathrm{NH}_{4}{ }^{+} \mathrm{e}$ catiões $\mathrm{Al}(\mathrm{III}), \mathrm{Fe}(\mathrm{III}), \mathrm{Cu}(\mathrm{II}))$. A interdisciplinaridade com a disciplina de Técnicas Laboratoriais de Geologia é também uma vertente a explorar [6].

\section{PARTE EXPERIMENTAL}

Em cada turma foi fornecida aos alunos a ficha de trabalho que se segue (omitindo a lista de material e reagentes, cuja elaboração fica a cargo dos alunos) pretendendo-se que cada sal fosse sintetizado por dois grupos, utilizando um grupo suporte e o outro não. Para além dos sais indicados na tabela 1 , tentou-se ainda a síntese do sulfato de amónio e ferro (III) dodecahidratado, embora sem resultado. Este caso é discutido no ponto 3 .

Posteriormente, aos grupos que sintetizaram o sulfato de alumínio e potássio dodecahidratado, foi ainda pedido que adicionassem sulfato de crómio(III) e potássio dodecahidratado às águas mãe da cristalização, cocristalizando uma solução sólida, de aspecto idêntico ao das ametistas e de algumas variedades de fluorite.

Os resultados obtidos encontram-se sumariados na tabela 2 .

\subsection{Ficha experimental: síntese de um sal duplo}

Lista de material e reagentes:

\begin{tabular}{ll}
\hline $\mathrm{K}_{2} \mathrm{SO}_{4}$ & óculos de protecção \\
$\mathrm{Al}_{2}\left(\mathrm{SO}_{4}\right)_{3}$ & copos de $150 \mathrm{~cm}^{3}$ \\
$\mathrm{Al}_{2}\left(\mathrm{SO}_{4}\right)_{3} \cdot 18 \mathrm{H}_{2} \mathrm{O}$ & proveta de $100 \mathrm{~cm}^{3}$ \\
$\left(\mathrm{NH}_{4}\right)_{2} \mathrm{SO}_{4}$ & varetas de vidro \\
$\mathrm{CuSO}_{4} \cdot 5 \mathrm{H}_{2} \mathrm{O}$ & vidros de relógio \\
$\mathrm{MgSO}_{4} \cdot 7 \mathrm{H}_{2} \mathrm{O}$ & espátula \\
amostras de rochas: & tenaz \\
mármore, arenitos, & \\
sílica, vulcanitos & papel absorvente \\
conchas rugosas & balança técnica \\
água destilada & placa de aquecimento \\
& termómetro $\left(0 \mathrm{a} 100^{\circ} \mathrm{C}\right)$ \\
& secador \\
& medidor de $\mathrm{pH}$ \\
& papel de pH \\
\hline
\end{tabular}

Se vai utilizar suporte inicie o seu trabalho no ponto 1 . Se não vai utilizar suporte inicie o seu trabalho no ponto 2 e ignore o ponto 6 .

1. Verifique se o suporte (rocha ou concha) está devidamente limpo e seco e determine a sua massa.

2. Escreva a equação química que traduz a síntese do sal duplo que lhe foi atribuído e calcule a massa de 
cada um dos reagentes a utilizar nessa síntese (ver tabela 1).

3. Pese os reagentes, introduzaos num copo de $150 \mathrm{ml}$ e adicionelhes o volume de água indicado na tabela 1.

4. Dissolva os sais a quente, registando a temperatura a que ocorre a dissolução. Não deve ultrapassar os $80^{\circ} \mathrm{C}$. De preferência esta parte do trabalho deve ser realizada na hotte.

5. Meça o pH da solução. Para soluções coloridas deve usar um aparelho de medida de $\mathrm{pH}$.
6. Coloque o suporte dentro da solução ainda quente, de modo a que este fique totalmente imerso. Registe e interprete a ocorrência de qualquer efervescência.

7. Tape o copo com um vidro de relógio e deixe-o em repouso num local onde a temperatura oscile pouco.

8. Se ao fim de dois dias não observar a formação de cristais, retire o vidro de relógio, de forma a permitir uma evaporação lenta do solvente.

9. Após alguns dias recolha os cristais obtidos. Observe-os atenta- mente e registe as suas características (forma, cor, formação no suporte ou fora deste, etc). Seque cuidadosamente os cristais com papel absorvente; se necessário utilize o secador a frio. Determine a massa da totalidade dos cristais formados.

10. Calcule o rendimento do processo.

11. Determine o ponto de fusão do sal sintetizado, pela técnica do capilar. Compare o resultado com o valor referido na tabela 1 .

\subsection{Resultados experimentais}

Tabela 2 - Síntese de sais duplos, resultados experimentais

\begin{tabular}{|c|c|c|c|c|c|c|c|c|c|}
\hline Sal a sintetizar & Sais iniciais & $\begin{array}{r}m \pm 5 \times 10^{-3} \\
(\mathrm{~g})\end{array}$ & $\mathrm{pH}$ & $\begin{array}{r}\mathrm{m} \pm 5 \times 10^{-3} \\
\text { (suporte) } \\
(\mathrm{g})\end{array}$ & $\begin{array}{r}\mathrm{m} \pm 5 \times 10^{-3} \\
\text { (cristais de } \\
\text { Suporte) } \\
(\mathrm{g})\end{array}$ & $\begin{array}{r}\mathrm{m} \pm 5 \times 10^{-3} \\
\text { (total de } \\
\text { cristais) } \\
(\mathrm{g})\end{array}$ & $\begin{array}{r}\eta \\
(\%)\end{array}$ & $\begin{array}{r}\text { p.f. } \pm 0.5 \\
\left({ }^{\circ} \mathrm{C}\right)\end{array}$ & $\begin{array}{r}\text { p.f } \\
\text { (médio) } \\
\left({ }^{\circ} \mathrm{C}\right)\end{array}$ \\
\hline Sulfato de & $\begin{array}{l}\mathrm{K}_{2} \mathrm{SO}_{4} \\
\mathrm{Al}_{2}\left(\mathrm{SO}_{4}\right)_{3} \cdot 18 \mathrm{H}_{2} \mathrm{O}\end{array}$ & $\begin{array}{r}5,55 \\
21,07\end{array}$ & 2,19 & $9,46(1)$ & 21,22 & 21,22 & 71 & $\begin{array}{l}93,0 \\
92,0 \\
91,0\end{array}$ & 92,0 \\
\hline $\begin{array}{l}\text { alumínio e } \\
\text { potássio } \\
\text { dodecahidrat. }\end{array}$ & $\begin{array}{l}\mathrm{K}_{2} \mathrm{SO}_{4} \\
\mathrm{Al}_{2}\left(\mathrm{SO}_{4}\right)_{3} \cdot 18 \mathrm{H}_{2} \mathrm{O}\end{array}$ & $\begin{array}{r}5,21 \\
20,10\end{array}$ & 2,15 & - & - & 23,45 & 83 & $\begin{array}{r}95,0(6) \\
93,5 \\
92,0\end{array}$ & 92,8 \\
\hline (alúmen) & $\begin{array}{l}\mathrm{K}_{2} \mathrm{SO}_{4} \\
\mathrm{Al}_{2}\left(\mathrm{SO}_{4}\right)_{3}\end{array}$ & $\begin{array}{r}5,50 \\
10,80\end{array}$ & 2,64 & $59,14^{(2)}$ & 6,11 & 6,52 & 22 & $\begin{array}{l}91,0 \\
92,0 \\
92,0\end{array}$ & 91,7 \\
\hline $\begin{array}{l}\text { Sulfato de } \\
\text { alumínio e }\end{array}$ & $\begin{array}{l}\left(\mathrm{NH}_{4}\right)_{2} \mathrm{SO}_{4} \\
\mathrm{Al}_{2}\left(\mathrm{SO}_{4}\right)_{3} \cdot 18 \mathrm{H}_{2} \mathrm{O}\end{array}$ & $\begin{array}{r}4,37 \\
21,55 \\
\end{array}$ & 2,12 & $13,06(3)$ & 20,81 & 21,19 & 72 & $\begin{array}{r}100,0^{(6)} \\
95,0 \\
95,0 \\
\end{array}$ & 95,0 \\
\hline $\begin{array}{l}\text { amónio } \\
\text { dodecahidrat. }\end{array}$ & $\begin{array}{l}\left(\mathrm{NH}_{4}\right)_{2} \mathrm{SO}_{4} \\
\mathrm{Al}_{2}\left(\mathrm{SO}_{4}\right)_{3} \cdot 18 \mathrm{H}_{2} \mathrm{O}\end{array}$ & $\begin{array}{r}4,17 \\
21,04 \\
\end{array}$ & 2,16 & $\begin{array}{r}76,23(4) \\
\text { (pirite) }\end{array}$ & 18,70 & 19,77 & 69 & $\begin{array}{l}97,0 \\
98,0 \\
96,0\end{array}$ & 97,0 \\
\hline (alúmen) & $\begin{array}{l}\left(\mathrm{NH}_{4}\right)_{2} \mathrm{SO}_{4} \\
\mathrm{Al}_{2}\left(\mathrm{SO}_{4}\right)_{3} \cdot 18 \mathrm{H}_{2} \mathrm{O}\end{array}$ & $\begin{array}{r}3,64 \\
20,94 \\
\end{array}$ & 2,18 & - & - & 18,38 & 74 & $\begin{array}{l}95,0 \\
95,0 \\
94,0\end{array}$ & 94,7 \\
\hline
\end{tabular}


Tabela 2 - Síntese de sais duplos, resultados experimentais (continuação)

\begin{tabular}{|c|c|c|c|c|c|c|c|c|c|}
\hline Sal a sintetizar & Sais iniciais & $\begin{array}{r}\mathrm{m} \pm 5 \times 10^{-3} \\
(\mathrm{~g})\end{array}$ & $\mathrm{pH}$ & $\begin{array}{r}\mathrm{m} \pm 5 \times 10^{-3} \\
\text { (suporte) } \\
(\mathrm{g})\end{array}$ & $\begin{array}{r}\mathrm{m} \pm 5 \times 10^{-3} \\
\text { (cristais no } \\
\text { Suporte) } \\
(\mathrm{g})\end{array}$ & $\begin{array}{r}\mathrm{m} \pm 5 \times 10^{-3} \\
\text { (total de } \\
\text { cristais) } \\
(\mathrm{g})\end{array}$ & $\begin{array}{r}\eta \\
(\%)\end{array}$ & $\begin{array}{r}\text { p.f. } \pm 0.5 \\
\left({ }^{\circ} \mathrm{C}\right)\end{array}$ & $\begin{array}{r}\mathrm{p} . \\
\text { (médio) } \\
\left({ }^{\circ} \mathrm{C}\right)\end{array}$ \\
\hline $\begin{array}{l}\text { Sulfato de } \\
\text { amónio e } \\
\text { magnésio } \\
\text { hexahidrat. } \\
\text { (Schönite) }\end{array}$ & $\begin{array}{l}\left(\mathrm{NH}_{4}\right)_{2} \mathrm{SO}_{4} \\
\mathrm{MgSO}_{4} \cdot 7 \mathrm{H}_{2} \mathrm{O} \\
\left(\mathrm{NH}_{4}\right)_{2} \mathrm{SO}_{4} \\
\mathrm{MgSO}_{4} \cdot 7 \mathrm{H}_{2} \mathrm{O}\end{array}$ & $\begin{array}{l}13,21 \\
24,65 \\
13,20 \\
24,66 \\
\end{array}$ & $\begin{array}{l}4,70 \\
4,87\end{array}$ & $\begin{array}{l}39,33^{(4)} \\
1,72^{(4)} \\
\text { (búzio) }\end{array}$ & $\begin{array}{r}11,65 \\
1,49\end{array}$ & $\begin{array}{l}12,30 \\
12,73\end{array}$ & $\begin{array}{l}34 \\
35\end{array}$ & $\begin{array}{r}\text { nada se } \\
\text { observou } \\
\left(\theta_{\mathrm{f}}=180\right) \\
\text { nada se } \\
\text { observou } \\
\left(\theta_{\mathrm{f}}=160\right) \\
\end{array}$ & - \\
\hline $\begin{array}{l}\text { Sulfato de } \\
\text { amónio }\end{array}$ & $\begin{array}{l}\left(\mathrm{NH}_{4}\right)_{2} \mathrm{SO}_{4} \\
\mathrm{MgSO}_{4} \cdot 7 \mathrm{H}_{2} \mathrm{O}\end{array}$ & $\begin{array}{l}13,21 \\
24,65 \\
\end{array}$ & 4,73 & $\begin{array}{l}3,30{ }^{(4)} \\
\text { (búzio) }\end{array}$ & 11,77 & 11,77 & 33 & $\begin{array}{r}\text { nada se } \\
\text { observou } \\
\left(\theta_{\mathrm{f}}=180\right)\end{array}$ & \\
\hline $\begin{array}{l}\text { magnésio } \\
\text { hexahidrat. } \\
\text { (Schönite) }\end{array}$ & $\begin{array}{l}\left(\mathrm{NH}_{4}\right)_{2} \mathrm{SO}_{4} \\
\mathrm{MgSO}_{4} \cdot 7 \mathrm{H}_{2} \mathrm{O}\end{array}$ & $\begin{array}{l}13,27 \\
24,65 \\
\end{array}$ & 4,89 & - & - & 12,98 & 36 & $\begin{array}{r}\text { nada se } \\
\text { observou } \\
\left(\theta_{\mathrm{f}}=175\right)\end{array}$ & \\
\hline \multirow{2}{*}{$\begin{array}{l}\text { Sulfato de } \\
\text { amónio e } \\
\text { cobre } \\
\text { hexahidrat. }\end{array}$} & $\begin{array}{l}\left(\mathrm{NH}_{4}\right)_{2} \mathrm{SO}_{4} \\
\mathrm{CuSO}_{4} \cdot 5 \mathrm{H}_{2} \mathrm{O}\end{array}$ & $\begin{array}{l}11,62 \\
21,56 \\
\end{array}$ & 2,81 & $\begin{array}{l}2,60 \text { (3) } \\
\text { (búzio) }\end{array}$ & 11,33 & 12,23 & 34 & d. 110 & \\
\hline & $\begin{array}{l}\left(\mathrm{NH}_{4}\right)_{2} \mathrm{SO}_{4} \\
\mathrm{CuSO}_{4} \cdot 5 \mathrm{H}_{2} \mathrm{O}\end{array}$ & $\begin{array}{l}11,40 \\
21,74 \\
\end{array}$ & 2,90 & $\begin{array}{l}3,38 \text { (1) } \\
\text { (búzio) }\end{array}$ & 0,21 & 11,12 & 32 & d. $100-110$ & \\
\hline (schönite) & $\begin{array}{l}\left(\mathrm{NH}_{4}\right)_{2} \mathrm{SO}_{4} \\
\mathrm{CuSO}_{4} \cdot 5 \mathrm{H}_{2} \mathrm{O}\end{array}$ & $\begin{array}{l}11,64 \\
21,96\end{array}$ & 2,82 & - & - & 15,31 & 44 & d. $110-113$ & \\
\hline
\end{tabular}

(1) - Observou-se reacção entre o suporte e a solução.

(2) - Observou-se reaç̧ão fraca entre o suporte a a solução.

(3) - Observou-se reacção intensa entre o suporte e a solução.

(4) - Não se observou reacção entre o suporte e a solução.

(5) - A maior parte do sal sintetizado foi perdido antes da determinação da sua massa.

(6) - Valor não incluído na média. d-decompõe-se

$\theta_{\mathrm{f} \text { - temperatura final de aquecimento }}$ (conseguida com banho de parafina)

\section{CONCLUSÃO E DISCUSSÃO}

As cristalizações foram feitas durante o Inverno, a uma temperatura ambiente relativamente baixa, oscilando entre os 6 e os $10^{\circ} \mathrm{C}$. A temperaturas superiores, e como medida preventiva para evitar variações de temperatura no local de crescimento dos cristais, recomenda-se a utilização de uma mala térmica ou banho maria[2]: na sequência do ponto 7 descrito na técnica, o copo com o vidro de relógio é colocado numa mala térmica contendo um pouco de água quente no fundo e todo o conjunto é tapado, tornando o processo de arrefecimento mais lento. Quando se tornar necessário recorrer ao frigorífico (principalmente no Verão) a mala permite evitar o arrefecimento brusco, que possivelmente levaria à formação de microcristais pouco desenvolvidos.

Os sais testados neste trabalho, à excepção do sulfato de amónio e ferro(III), conduziram a bons resultados.

Fez-se a síntese do sulfato de alumínio e potássio a partir do sulfato de alumínio octodecahidratado e do sulfato de alumínio anidro. No primeiro caso obtiveram-se rendimentos muito superiores aos do se- gundo, sendo os primeiros da ordem dos $75 \%$ e os segundos dos $30 \%$. Os valores do ponto de fusão indicam que em ambos os casos se obteve o sal duplo esperado, já que os valores obtidos experimentalmente são concordantes com os citados na literatura [7] (tabela 2). Uma razão possível para esta diferença de rendimentos pode ser o facto de o sulfato de alumínio anidro não se encontrar com um grau de pureza aceitável, tanto mais que todas as soluções preparadas com este sal apresentavam à partida um aspecto turvo, devido à presença de um sólido branco em suspensão. Por este motivo utilizou- 
-se um excesso de $20 \mathrm{~cm}^{3}$ de água na preparação destas soluções.

$\mathrm{Na}$ síntese do sulfato de alumínio e amónio obtiveram-se rendimentos da ordem dos $70 \%$ e pontos de fusão sistematicamente superiores aos valores citados na literatura $[7,8]$. Não foi encontrada qualquer explicação para este facto.

$\mathrm{Na}$ síntese das schönites obtiveram-se rendimentos entre os $32 \%$ e $45 \%$, valores muito inferiores aos obtidos nas sínteses dos alúmenes.

Não se conseguiram determinar os pontos de fusão das schönites sintetizadas. No caso do sulfato de amónio e magnésio hexahidratado não se observou qualquer alteração por aquecimento até temperaturas da ordem dos $180^{\circ} \mathrm{C} 2$. O sulfato de amónio e cobre(II) hexahidratado decompôs-se a cerca de $110^{\circ} \mathrm{C}$, passando a apresentar a cor característica do sulfato de cobre(II) hidratado, apesar de na literatura [7] apenas se referir que este sal funde a uma temperatura superior a $120^{\circ} \mathrm{C}$.

Ao analisar a influência da presença de um suporte no rendimento do processo, verifica-se que, em condições idênticas, se obteve menor rendimento sempre que a cristalização ocorreu sobre um suporte. São de salientar as diferenças superiores a $10 \%$ (tabela 2) nos casos do sulfato de alumínio e potássio dodecahidratado e do sulfato de amónio e cobre(II) hexahidratado. Nos restantes sais as diferenças observadas são muito pequenas, podendo não ser significativas. Nalguns casos, estas diferenças de rendimento podem ser atribuídas à reacção do suporte com a solução. Estes casos encontram-se discutidos na literatura [6].

Determinou-se o ponto de fusão dos cristais das soluções sólidas de sulfato de crómio(III) e potássio dodecahidratado e sulfato de alumínio e potássio dodecahidratado, tendo-se observado que entre 86 e $89^{\circ} \mathrm{C}$ o sólido passava da cor roxa para a cor verde. Estas cores devem corresponder, respectivamente, à estrutura do complexo hexaquocrómio(III), que se mantém na solução sólida e, muito provavelmente, ao sulfato de
crómio(III), o que sugere a decomposição do sal duplo de crómio(III) antes da fusão. Atendendo aos valores referidos na literatura $[7,8]$ para os pontos de fusão dos componentes desta mistura, nomeadamente 92,5 ${ }^{\circ} \mathrm{C}$ para o sulfato de alumínio e potássio dodecahidratado e $89^{\circ} \mathrm{C}$ para o sulfato de crómio (III) e potássio dodecahidratado, estes resultados são anómalos: seria de esperar que o intervalo de fusão ocorresse numa gama de temperatura ligeiramente superior (acima do ponto de fusão do sal de crómio). Para esclarecer este fenómeno determinaram-se os pontos de fusão dos dois sais duplos, pela técnica do capilar, usando banho de água e com um aparelho automático de medida de ponto de fusão, Leica Galen III, que funde a substância através do aquecimento eléctrico de uma placa metálica. Os resultados obtidos para o sulfato de alumínio e potássio dodecahidratado são consistentes com os da literatura, mas para o sulfato de crómio (III) e potássio dodecahidratado observouse novamente o aparecimento da cor verde entre 86 e $90^{\circ} \mathrm{C}$, em ambas as técnicas. Estes resultados sugerem que o valor referido na literatura para o ponto de fusão deste composto deve ser revisto, tendo em conta a sua possível reacção de decomposição.

Não se conseguiu sintetizar o sulfato de amónio e ferro (III). Para a síntese deste sal seguiu-se um processo análogo ao dos restantes sais. Ao fim de alguns dias não ocorreu qualquer cristalização, tendo-se, no entanto, formado um precipitado. Tentou-se medir o ponto de fusão deste, pela técnica do capilar, não se observando qualquer alteração, por aquecimento até a uma temperatura de $60{ }^{\circ} \mathrm{C}$. Como o ponto de fusão indicado na literatura [7] para o sal duplo é de $40^{\circ} \mathrm{C}$, exclui-se assim a hipótese desse precipitado ser o produto pretendido. Atendendo à sua cor, supôs-se que fosse sulfato de ferro(III). Seguidamente concentraram-se as soluções, por evaporação do solvente, continuando a não se observar qualquer cristalização e vol- tando a obter-se um precipitado análogo. Por fim evaporaram-se as soluções até à secura, obtendo-se dois sólidos que pela sua cor aparentavam ser os reagentes. Note-se que estas soluções foram sempre aquecidas a uma temperatura máxima de $40^{\circ} \mathrm{C}$, dado que na literatura [7] se refere que o sulfato de ferro(III) se decompõe em água quente. As possíveis explicações para este insucesso são: a fraca solubilidade em água do sulfato de ferro(III) anidro [8]; a maior solubilidade do sal duplo, que neste caso é superior à do sal de ferro(III) de partida; a possibilidade da precipitação do hidróxido de ferro(III), que pode ocorrer nas condições experimentais de $\mathrm{pH}$ deste trabalho $(\mathrm{pH}$ $\sim 1,6)$ [9]. Numa tentativa de evitar a formação do hidróxido baixou-se o $\mathrm{pH}$ da solução, por adição de ácido sulfúrico concentrado à mistura reagente. Não se observou a formação do precipitado, mas também não se obtiveram cristais.

Neste trabalho os alunos aplicaram os conhecimentos aquiridos sobre escrita e acerto de reacções químicas, cálculos estequiométricos, rendimento de um processo, cristalização, medida do ponto de fusão, critério de pureza, identificação de substâncias, noção de pH. Aprenderam a medir o pH de uma solução com um aparelho automático de medida, o que é recomendável, em particular no caso de soluções coradas. Tomaram contacto com a ocorrência de processos paralelos, com a não neutralidade de soluções salinas, com o conceito de solução sólida, com a diferença entre precipitação e cristalização $^{3}$ e com formas de solucionar problemas práticos, como por exemplo, voltar a evaporar parte da solução quando não ocorre cristalização, ou filtrá-la quando há resíduos visíveis.

Parte dos insucessos das cristalizações são devidas ao baixo grau de pureza dos reagentes. Recomenda-se por isso a utilização de reagentes de grau puro e não a de reagentes comerciais, não sendo no entanto necessária a utilização de reagentes pro análise. 


\section{AGRADECIMENTOS}

As autoras agradecem ao Ministério da Ciência e da Tecnologia o financiamento para o projecto "As Rochas Ornamentais e os Minerais Sintéticos", Programa Ciência Viva 96/97 e à Escola Secundária Padre Alberto Neto a receptividade para a realização do projecto. Aos alunos dos $11^{\circ} \mathrm{L}$ e $11^{\circ} \mathrm{J}$ desta escola, agradecem a colaboração e o interesse que sempre demonstraram na realização dos trabalhos práticos e na execução dos respectivos relatórios.

* Centro de Química Estrutural e Departamento de Engenharia Química do Instituto Superior Técnico, Av.Rovisco Pais, 1096 Lisboa Codex

** Escola Secundária Padre Alberto Neto, Av. Paiva Conceiro, 2745 Queluz

A. T. Sousa é colaboradora do Centro de Química Estrutural no programa Ciência Viva.
NOTAS

1 Salvo se houver interesse na demonstração dessas propriedades.

2 Os dados de temperatura determinados neste trabalho são referidos à escala IPTS-68. A diferença para a escala ITS-90 às temperaturas de trabalho e atendendo aos erros experimentais, não é significativa.

3 llustrada na tentativa de síntese do sulfato de amónio e ferro (III) e na dissolução do sulfato de alumínio anidro.

\section{BIBLIOGRAFIA}

1. C. Teixeira, A. Santana, C. Mesquita, Boletim da Sociedade Portuguesa de Química, 53 (1994) 50.

2. C. Teixeira, O Livro das Pedras: Manual dos Sistemas Modulares para Cristalização "On The Rocks", ed. do autor (Novembro de 1995). Inclui video "Rochas Ornamentais e Minerais Sintéticos"

3. C. Teixeira, Manual de Experiências das Acções de
Formação do FOCO - "As Rochas Ornamentais no Ensino da Química", Instituto Superior Técnico (1996).

4. J. C. Bailar, H. J. Hemeléus, R. Nyholm, A. F. Trotman-Dickenson, Comprehensive Inorganic Chemistry, Vol I, Pergamon Press (1973).

5. C. Teixeira, M. J. Rodrigues, I. Silva, M. C. Silvério, M. F. Coelho, A. A. Gomes, A. M. Morais, M. F. Soares, Métodos de Cristalização. Aplicações no Ensino Secundário a submeter.

6. C. Teixeira, M. J. Rodrigues, I. Silva, M. C. Silvério, M. F. Coelho, A. A. Gomes, A. M. Morais, M. F. Soares, Cristalização sobre Suportes Rugosos. Aplicações no Ensino Secundário, a submeter.

7. D. R. Lide, CRC Handbook of Chemistry and Physics, 74 th edition (1994).

8. R. H. Perry, D. W. Green, Perry's Chemical Engineers' Handbook, 6 th edition, McGraw Hill editor (1984).

9. V. N. Alexéev, Semimicroanálisis Químico Cualitativo, Editorial Mir Moscú (1975).

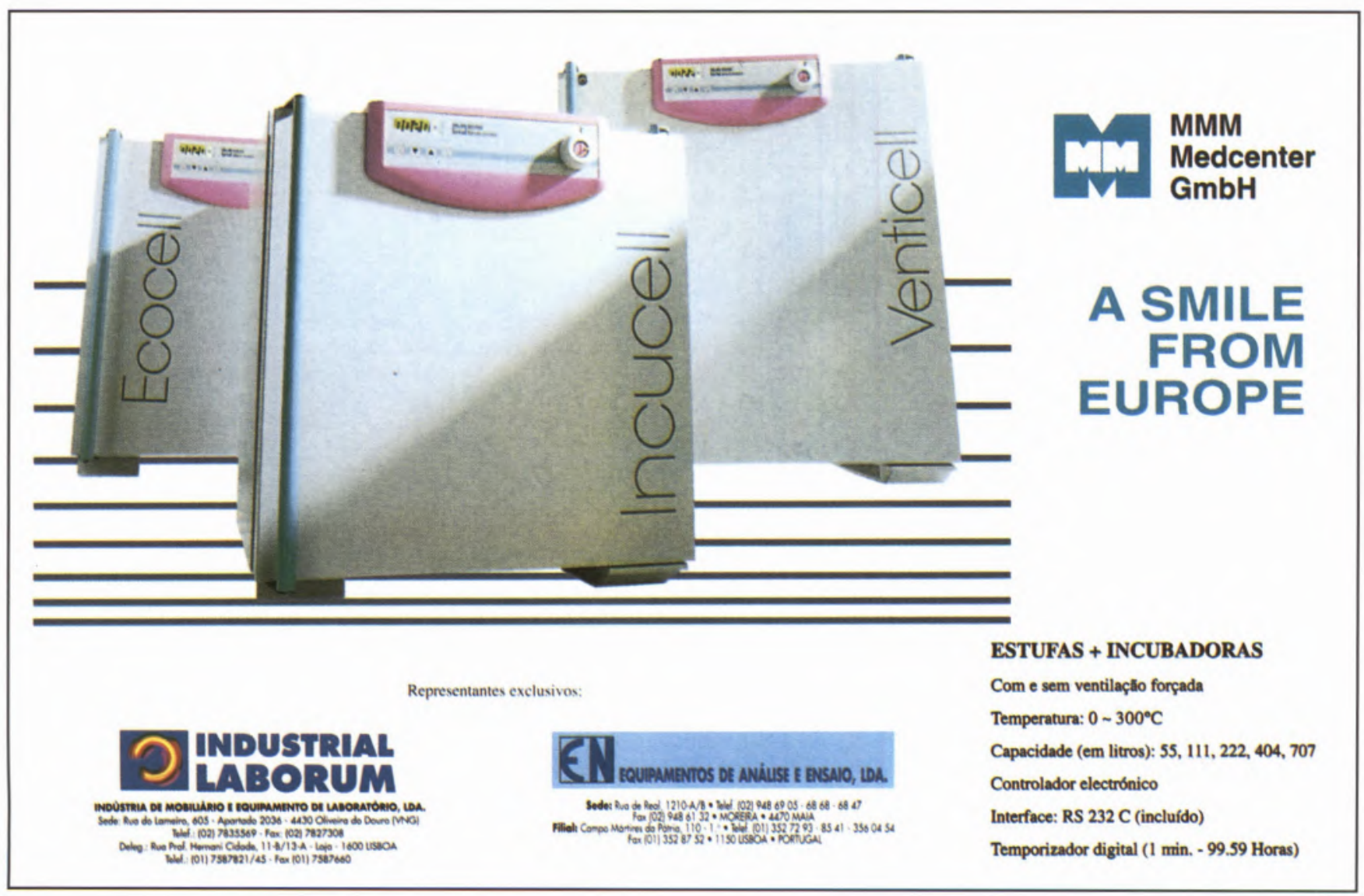

